\title{
A case study of mobile advertising in South Korea: Personalisation and digital multimedia broadcasting (DMB)
}

Received (in revised form): 13th January, 2008

\author{
Mi Jung Kim \\ is a Master's student in the Department of Advertising at the University of Florida. She obtained her BA in Mass Communication from Kyungpook \\ National University, Daegu, South Korea. Her research intersts are mobile advertising, new media marketing communication, media management \\ and telecommunication.
}

\section{Jong Woo Jun}

is a full time lecturer at the School of Communications, Dankook University, Seoul, South Korea. He earned his PhD at the Department of Advertising at the University of Florida. Previous to his study, he worked in the advertising business. He received a BA and MA, both in mass communication from the Hankuk University of Foreign Studies, Seoul, South Korea. His research interests include international branding and event marketing.

\section{Keywords mobile advertising, mobile marketing, personalisation, digital multimedia} broadcasting, Korea

\begin{abstract}
This study explores cases of mobile marketing in South Korea, one of the leading countries in terms of mobile industries. By analysing mobile advertising cases, including that of digital multimedia broadcasting, this study documents the current market situation and the effectiveness of marketing in the South Korean market. The findings show that mobile advertising in South Korea is quite advanced, and personalisation is brought to life through consumer and location targeting. The managerial implications of these findings are discussed in the conclusion.
\end{abstract}

Journal of Targeting, Measurement and Analysis for Marketing (2008) 16, 129-138. doi:10.1057/jt.2008.5

\section{INTRODUCTION}

Now, as the penetration rate of mobile phones has exceeded those of personal computers in many markets, it is believed that mobile media have become dominant as personal devices for communication. Accordingly, marketers and advertisers are considering the need for a mobile commerce revolution. ${ }^{1}$ In this fast growing mobile communication environment, cell phones are no longer just voice communication devices. The technological convergence of mobile phones with audio, video, computing, telecommunications and television has turned them into increasingly effective media for consumer advertising. ${ }^{1}$ Cell

Correspondence: Mi Jung Kim, University of Florida, FL, USA

Tel: +1 3526721108 ;

E-mail: genesis1116@gmail.com phones are, however, private communication devices unlike other communication media. Because of this differentiating characteristic, the extent of personalisation employed in mobile commerce is a topical issue in the market.

Even though the mobile industry is developing all over the world, its growth rate and its popularity are higher and more distinctive in Asian countries such as South Korea, Japan and China. In particular, South Korea is said to be one of the leading countries in terms of mobile technology including digital multimedia broadcasting (DMB) services. In this regard, it would be helpful to analyse the South Korean mobile industry and what are regarded as its cutting edge marketing propositions. The main objectives of this study are therefore: (1) to explore the current situation of the Korean mobile market, and (2) to analyse and explore mobile 
advertising propositions including DMB. This case study will have important managerial implications for mobile practitioners as well as for academics.

\section{LITERATURE REVIEW}

\section{Mobile marketing and advertising}

The Mobile Marketing Association (MMA) states that 'Mobile Marketing is the use of wireless media as an integrated content delivery and direct response vehicle within a cross media or standalone marketing communications program'. Mobile marketing has emerged from the internet revolution, and has become extremely topical among marketers. According to the overview of mobile industry by the MMA, mobile telephony is 'one of the first new channels to arise in over 50 years, to have quickly become a primary means of reaching out to our customers'. ${ }^{3}$ Similarly, the Wireless Advertising Association (WAA) defines mobile marketing as 'sending advertising messages to mobile devices such as mobile phones or PDAs through the wireless network'. ${ }^{4,5}$ Another definition of mobile advertising is to transmit promotional messages to consumers in the form of time and location sensitive, personalised information through using interactive mobile media. ${ }^{6}$

In short, mobile advertising is the communication of information about products, services or ideas using mobile devices. ${ }^{7}$ The web's interactive and quickresponse capabilities via mobile phones have definitely helped them to become a direct marketing channel. ${ }^{8}$ Cyriac Roeding, European chair of the MMA suggests that, 'mobile advertising will be one of the most important revenue generators for mobile operators' (DeZoysa, ${ }^{9}$ p. 8). Moreover, the high penetration rate of mobile phones has contributed towards the increased delivery of advertisements for products and services. ${ }^{10}$

\section{Types of mobile advertising}

Marketers believe that if they can send the right message to the right person at the right time, it will affect consumers' behaviour. ${ }^{11}$ To marketers, mobile advertising heralds a new era of marketing communications. Mobile advertising began with short messaging service (SMS) advertisements on mobile phones. The existing literature suggests that mobile advertising increases brand recall and brand association, ultimately leading to purchase intent. ${ }^{12}$ Thus, SMS was widely used and succeeded as a new way of advertising., ${ }^{5,10}$ The multimedia message service (MMS) is increasingly being used in mobile campaigns, especially in Asia and Europe. ${ }^{13}$ MMS advertisements consist of digital image inputs (eg graphics and audio clips), which can be more creative and effective. ${ }^{12,14}$

More recently, mobile advertising is integrating SMS, MMS and other channels to help customers obtain information. ${ }^{11}$ For instance, consumers can participate in a competition or vote for a television programme or download a coupon and a ringtone from a newspaper. This kind of mobile advertising has proved successful and is still becoming more popular. ${ }^{11}$ According to the Mobile Advertising Industry Survey ${ }^{15}$ in 2004, the most widely used platforms for delivering mobile advertising were a combination of SMS (35.2 per cent), Wireless Application Protocol (WAP) (9.0 per cent), multimedia audio (3.3 per cent), voice activation (4.1 per cent) and i-mode( 2.5 per cent).

Furthermore, the growth of the mobile internet and DMB services will be the next big change in mobile advertising. The combination of different types of mobile advertising will allow marketers and advertisers to deliver more attractive messages and content to their customers.

\section{Targets of mobile advertising}

Some previous studies of mobile advertising discuss audience impacts on mobile advertising. Pagani ${ }^{16}$ studies user technology acceptance and establishes the model of consumer adoption of $3 \mathrm{G}$ mobile multimedia services. She concludes 'perceived usefulness, ease of use, price, and speed of use are the most important determinants of adoption of multimedia mobile services, in that order' (Pagani, ${ }^{16}$ p. 46). According to age groups or adopter segments (eg innovator, early adopter, early majority, late majority, late comer), the importance of these determinants differs. Another study on the consumer perspective of mobile advertising indicates that the message content is related to the perceived mobile advertising value by mobile users. ${ }^{6}$ This study also suggests that perceived mobile advertising value differs by age group. 
In this regard, data taken from the Mobile Advertising Industry Survey ${ }^{15}$ in 2004 suggest that the first three segments targeted most by mobile advertising were youth (49.2 per cent), mass consumers (29.6 per cent) and early adaptors (15.7). Respondents of this industry survey considered the ability to target an audience precisely as the most important factor for the success of mobile advertising.

\section{Drivers and limitations of mobile advertising}

Mobile Advertising Industry Survey ${ }^{15}$ in 2004 also indicates that the main drivers in the development of mobile advertising are personalised mediums; user facility for being able to opt-in; 'call to action' (ie immediate response facility); location specific, interactive profiling; appeal to younger customers; and one-to-many communication. The main inhibitors in the development of mobile advertising are intrusiveness (invades privacy); handset usability; small format/screens; text-based/limited graphics; payment security; bandwidth limitations; a new and untried medium; and the lack of industry standards negatively impacting on brand building.

Mobile advertising has critical limitations owing to the fact that it is a private medium. According to Jun and Lee, ${ }^{17}$ college students' attitudes toward mobile advertising are negative and the situation is worse as concerns behavioural intentions regarding mobile advertising. This means that mobile advertising should be managed with caution. Related to this is a study about privacy and online shopping, which suggests that, given the right circumstances, online users easily forget about their privacy concerns and communicate even the most personal details without any compelling reason to do so. ${ }^{18}$

\section{Personalised mobile advertising}

Mobile advertising has earned significant attention because of its unique attributes, such as personalisation, that offer new opportunities to advertisers to place effective and efficient promotions on mobile environments. ${ }^{5}$ Personalisation is used to offer individualised content to each consumer. ${ }^{19}$ Personalisation has been studied based on the literature of relationship marketing and customer relationship management. ${ }^{20}$ There are many different definitions of personalisation in the marketing field. ${ }^{21-25}$ The definition by Imhoff et al. ${ }^{21}$ is relatively more suitable to mobile advertising than others. It defines personalisation as 'the ability of a company to recognise and treat its customers as individuals through personal messaging, targeted banner ads, special offers on bills, or other personal transactions' (Imhoff et al., ${ }^{21}$ p. 467). Furthermore, other studies about mobile advertising have emphasised the importance of the personalisation approach. ${ }^{1,5,20}$

According to a Mobile Advertising Industry Survey by WAA in 2004, 92 per cent of mobile advertising professionals believe the medium must be personalised in order to succeed. Reza Chady, the head of global market research at Nokia Networks, states that customers are likely to receive and accept advertising that is personalised and relevant to their lifestyle. ${ }^{9}$

For mobile advertising, the key point is to identify what customers want most from their mobile phones. ${ }^{1}$ Robins ${ }^{1}$ claimed that the adoption of wireless broadband in mobile phones relies on personalised information services for the user. Moreover, a survey by Accenture, which explored US and UK mobile phone and PDA users, found that people are happier when receiving un-requested promotional messages if the messages were personalised and relevant. ${ }^{1}$ Another study found that 10 per cent of phone customers and 25 per cent of PDA owners had already used their mobile devices to buy goods. ${ }^{26}$

Since mobile phones are individually identifiable, they are well suited to provide accurately personalised services and information. ${ }^{1}$ Personalisation can enable marketers to reach their potential customers in a very individualised way and thus strengthen the relationship with the consumers. ${ }^{5}$ Personalised mobile advertising, therefore, refers to sending advertising messages to mobile devices such as mobile phones through the wireless network, based on the customers' user demographics, user preference, context and content factors. ${ }^{5}$ 


\section{CASE ANALYSIS}

This study chooses South Korea as the analysis target in terms of the mobile industry and mobile advertising. Based on a literature review, this study explores South Korean cases of mobile industry situations, how mobile advertising strategies and its executions work and how marketers personalise advertising messages in the South Korean market.

\section{Mobile market situation of South Korea}

The mobile phone is becoming a primary means of communication, not only for voice but also for digital services, e-mail, digital photos, navigation and other mobile services. ${ }^{2}$ This trend is prevalent across the globe. It is rapidly gaining popularity in Asian countries such as Japan, Korea and China. Among these big mobile phone markets, the Korean market has been growing enormously as its market changes and the trends of mobile phone subscriptions show.

A government-owned company and the first mover within the telecommunication industry, Korea Mobile Telecom (KMT) started their mobile telephone service in Korea in 1984. In 1994, KMT became a member of the SK Group and changed its name to SK Telecom. The South Korea market structure, however, changed in 1996 in allowing entrance to new players, Shinsegi Telecom joined the market in 1996 as well as KT Freetel (KTF), Hansol M.com and LG Telecom jumped into the growing market in the late 1997. With increased competition, these five companies have fought hard to gain new subscribers resulting in a rapid increase in the number of mobile phone users in South Korea. While there were only six million mobile service subscribers in 1997, by June 2001 the number had reached around 28 million (57 per cent of the south Korean population). Subsequently, the subscriber base reached to more than 36 million in 2004 (Table 1). In addition, according to mobile phone distribution by age group data, ${ }^{27}$ the popularity of mobile phones in South Korea is most evident among the younger generation (Table 2 ).

Furthermore, age group 20-29 is about seven times more likely to have a subscription than age group 50-59.

During this period of rapid growth of the mobile phone market, the five mobile operators used new marketing strategies to acquire new subscribers. They provided discounts and subsidies on handsets in order to increase their market share and gain more market power. This change in the market structure specifically put new entrants to the industry in serious financial problems. Eventually this led to companies merging and acquiring one another. In 2000, SK Telecom acquired Shinsegi Telecom and KTF acquired Hansol M.com. The competitive situation had, however, shifted in 2000 as the Ministry of Information and Communication prohibited discounts and subsidies on handsets. ${ }^{28}$

In recent years, Korean telecommunication companies have changed from $2 \mathrm{G}$ to $2.5 \mathrm{G}$ and on to $3 \mathrm{G}$ networks and they have improved their services. ${ }^{29}$ In 1999, LG Telecom was the first to offer WAP services. Then KTF followed and SK Telecom provided the same service in 2000 . As a result, the Korean mobile phone market has become one of the most advanced in the world.

Table 1: Subscriber growth: Korean mobile telephony market (2005)

\begin{tabular}{lllll}
\hline 2000 & 2001 & 2002 & 2003 & 2004 \\
\hline $26,810,000$ & $29,040,000$ & $32,340,000$ & $33,060,000$ & $36,590,000$ \\
\hline
\end{tabular}

Source: inews24.com '2005 Korean mobile yearbook'.

Table 2: Mobile phone distribution by age (1999)

\begin{tabular}{llllll}
\hline $\mathbf{1 3 - 1 9}$ & $\mathbf{2 0 - 2 9}$ & $\mathbf{3 0 - 3 9}$ & $\mathbf{4 0 - 4 9}$ & $\mathbf{5 0 - 5 9}$ & Total \\
\hline 0 & $7,350,000$ & $5,090,000$ & $3,020,000$ & $1,360,000$ & $16,820,000$ \\
\hline
\end{tabular}

Source: Cheil Communication (1999). 


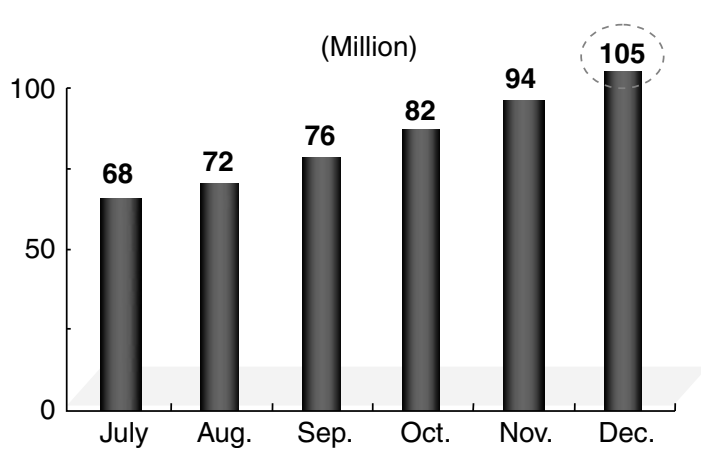

Figure 1: : The number of DMB service subscribers (2006) Source: Industry report of TU

Furthermore, Korea is the first country in the world to offer mobile television content on cellular phones. Within two years of its introduction in Korea, the subscribers of mobile television reached seven million throughout the world. $^{30}$

Customers have access to a wide variety of mobile services. In particular, DMB has been popular in Korea. Telecommunication companies in Korea have provided this service since 2005. For the DMB service, the subscribers of mobile phones can get the programmes they want to watch on their phone by paying additional fees (Satellite-based DMB- \$12/month, Terrestrial DMB- Free). ${ }^{30}$

Since DMB's inception, the number of DMB users has increased (Figure 1). In 2006, the DMB audience reached more than 105 million. The small screen on the personal cell phone is not an obstacle to the diffusion of mobile television service in Korea. This trend of DMB mobile phone service suggests to us that mobile phones have the potential and capability as a medium for advertising.

Overall, the mobile telephone market in Korea is rapidly increasing and subscriber adaptability to technological development is high enough to justify new services. Furthermore, the use of DMB service on mobile phones has increased, so advertising strategies and tactics can be diversified. This, in turn, benefits advertisers and marketers who endeavour to provide more effective advertising messages to their consumers. Furthermore, in 2004 the Korean Marketing
Association expected that the Korean mobile advertising market size would be $\$ 190 \mathrm{bn}$, and would grow to $\$ 630$ bn in $2005 .{ }^{31}$

\section{Korean mobile advertising types}

Mobile advertising is one of the contents offered by content providers of telecommunication companies. The first step in the flow of mobile advertising service is the sending of programmed advertisements from servers. The second step involves the automatic saving and installation of the sent advertisement in the users' handset. In the third step, the ad automatically appears on the screen when users use their mobile phones. The different types of mobile advertising typically used in Korea are SMS, Event Number, Mobile Coupon and BizRing.

\section{Short message service}

The first type of mobile advertising, SMS, has been widely used. Considered the backbone channel of mobile advertising, the processes of its operation are targeting by location; then, targeting by age, gender and occupation; sending a message to targets; and connecting to the advertising pages. The salient feature of SMS is that it embodies the concept of one-to-one interactive communication with consumers who want an advertising message. SMS is based on optimal targeting by analysing trends and patterns of consumer behaviour. Such information, identifying the demographic information of consumers, has been accumulated for a decade.

In addition to the demographic factors, time, location, recent action and contents can be the targeting criteria. Marketers can send a mobile advertisement to their target audience at a certain time by being matching consumer data with the campaign object. Moreover, the frequency of advertisement exposure can be diverse. For instance, a promotional message for fast food restaurants tends to be sent at lunchtime. Also, consumers can receive different advertising messages according to where they are located. Responsive action to the mobile advertisement by the recipient can then be used in deciding whether a follow-up message should be sent or not. Another way to choose the target market and 
send the right messages is to send advertising content similar to those which consumers responded to earlier. The basic assumption is that the content the consumers reacted to also reflect their interests.

Specifically, in 2004 by using MAIS ${ }^{\text {TM }}$, which is a highly advanced analysis system, in the industry report of AirCROSS it was reported that the response rate of mobile advertising was increased by 66 per cent compared to general commercials. The results indicated that consumers who received mobile advertising participated in promotional events more than those who were exposed to off/online advertising messages.

\section{Event number}

The second type of mobile advertising is event number. Event number is the trigger for interactive communication with consumers. This mobile advertising method is used as a media mixing tool. It is linked with all media such as television, newspaper, magazine, internet and billboard.

Its purpose is to attract consumers to use their mobile phones. The form of event number is $\star \star+$ event numbers (ex. 1234) and it is included in the commercials of other media. For instance, in print advertisement, the event number can be presented so that consumers can dial that number with their mobile phones to participate in the event.

\section{Mobile coupons}

The third type of mobile advertising is the mobile coupon. Mobile coupons are convenient to keep and carry so that consumers tend to be willing to get them. Thus, the advertising campaign using mobile coupons, which need the consumer's authorisation, can be utilised. When coupons are sent, the consumers' preference, age, gender, location are considered as main factors in determining which coupons go to whom. Resultantly, coupons can influence consumers to visit the offline stores and to buy products.

\section{BizRing}

The last type of mobile advertising is BizRing, which offers an advertising message instead of a connection tone when consumers are calling in to their companies. In Korea, it is common to use music or comment as connection tones for mobile phones. Naturally, consumers are exposed to an advertising message. BizRing is also effective for capturing attention because consumers tend to think it is interesting.

\section{MoA}

MoA is two-way interactive multimedia advertising provided by SK Telecom, which is offered on mobile phone screens. The framework of this advertising communication includes mass and targeting marketing, interactive media and value creating $\mathrm{M}$-Commerce through which companies can brand their products or organisations, market themselves, and plan events and/or promotions. Consumers, as the end users, get benefits from this communication process such as advertisements, information and entertainment, event and/or promotion information, and a variety of additional benefits.

MoA is a powerful mobile medium based on 130,000 subscribers who have both loyalty and purchasing powers at the same time. Consumers can be classified into two categories by gender and location. The number of male consumers is more than female (Table 3), and people who locate in the metropolitan area constitute almost

Table 3: The MoA subscribers distribution by gender (2005) (0000)

\begin{tabular}{llllll}
\hline & $\mathbf{1 9}$ or less & $\mathbf{2 0 - 2 9}$ & $\mathbf{3 0 - 3 9}$ & $\mathbf{4 0 - 4 9}$ & $\mathbf{5 0}$ or $\mathbf{m o r e}$ \\
\hline Male & 4.0 & 24.4 & 15.3 & 8.7 & 5.2 \\
Female & 4.3 & 21.5 & 8.7 & 4.9 & 3.2 \\
Total & 8.3 & 45.9 & 14.0 & 13.6 & 8.4 \\
\hline
\end{tabular}

Source: The Industry Report of AirCROSS. 
half of all subscribers according to the industry report. From these data, marketers and advertisers identify their target markets and can effectively design their marketing programmes.

The characteristics of MoA as an advertising medium are efficiency and effectiveness, resulting from repetitive exposure and targeting. Moreover, a survey of brand and advertisement awareness indicates that consumers who are exposed to MoA tend to recognise these factors better than before exposure to MoA. Moreover, when compared to television commercials, MoA is more cost-efficient in cost/benefit terms. Compared to the existing five main media of television, radio, newspaper, magazine and billboard, the degree of attention is high. The exposure rate is also high. Its measures of advertising effectiveness and response are relatively accurate compared to other media. Its flexibility also allows it to be integrated with other media. Lastly, there is less restriction on time and location when utilising MoA.

The operating process of MoA consists of targeting and downloading. In other words, subscribers who are targeted receive a message. They can then download advertisements or promotion coupons via network. In the exposure process of MoA, a consumer will get a maximum of ten unsolicited messages a day during the hours of 8 a.m. -6 p.m. The advertising content of MoA consists of short video clips each playing for a maximum of $10 \mathrm{~s}$ and it consists of three different messages a day.

\section{Successful cases of Korean mobile advertising}

There have been three successful mobile advertising campaigns in Korea. The first case is BMW's New 3 series promotion. They provided two event promotional advertising messages from 28th February to 31st March and from 6th April to 15th April both in 2005. For the promotion of their client's product, a movie of BMW New 3 series cars was used both by, SMS and event number ( $\star \star 357)$, and MoA was used to send advertising messages. The main message was designed to attract consumers to visit their mobile site, solve a quiz about the movie, and download the video, and participate for a trial drive. Finally, lots were drawn and prizes were given out to the participants. The prizes were movie tickets for 625 people (two tickets for each person). The second event-advertising message was designed to make consumers visit the BMW mobile site, play games and participate in a quiz. The prize for 400 participants was BMW miniature, worth $\$ 50$ each. The results of this promotional event using mobile advertising were satisfying. The rate of response was 12 per cent, indicating that they could generate the potential consumers. The hit rate of their mobile site was 2,700,000, and their catalog was downloaded 50,000 times. Furthermore, about 4,000 people applied for a trial drive.

The second successful case was the client ESTEE LAUDER's promotion of their new product, Pure Pops. They sent mobile coupons to consumers designed to make people visit the department store and get samples using the coupons. They used SMS, event number $(\star \star 357)$ and MoA. They prepared 25,000 Pure Pops for this event. The promotion period was February 2005. In this case, the mobile advertising effect was eight times higher than off/online advertising. The samples ran out fast; product awareness was increased and most importantly sales of the department stores were increased due to this event.

Another successful implementation of mobile advertising was the promotion of a new shaver, XPEC3, by Doruco. Doruco offered a XPEC3 to 500 people every week. The period of this event was from 30th March to 8th May, 2005. They promoted their new product by holding offline events in the downtown district and the baseball stadium and sent mobile advertisements. They used SMS, event number $(\star \star 3333)$ and MoA. They offered 25,000 samples to consumers. They reported that the samples ran out fast everyday during the promotion period. Moreover, their sales increased by an average of 20 per cent during the campaign. The hit rate of their XPEC3 mobile site was 360,000 a day, and the coupons were downloaded 40,000 times. 


\section{Mobile advertising in the world}

Successful mobile advertising cases are found in countries other than South Korea. Pepsico China targeted the younger generation and carried out mobile advertising to intercommunicate with them in 2007. Pepsico China conducted a CNY WAP campaign site designed to allow their consumers to download video clips. Moreover, they provided MMS mobile advertising service and electronic postcards for the New Year. During the mobile campaign period, the impression rate for the Pepsico WAP site reached to $8,000,000 .{ }^{31}$

On the other hand, although the popularity of mobile advertising in the US is lower than Asian countries, the US mobile advertising market has potential. For example, the successful case in the US is the Coca-Cola company's mobile branding campaign in 2007. They also provided an M-card, which is an electronic postcard to mobile users who permitted the mobile advertising that they had received. The result was that more than 55,000 users had participated in the mobile campaign. $^{31}$

Another good example of mobile advertising can be found in Turkey. From February of 2007, Efes Pilsen, a Turkish beer brand, is sponsoring and providing all sports content via mobile WAP service. ${ }^{31}$ Through this service users can get upto-date news and information about sports in various forms of mobile advertising.

From these successful cases of mobile advertising in different countries it is clear that mobile advertising is working as a new and effective way of communication in marketing, although the acceptant rate or speed may differ from culture to culture.

\section{DMB mobile advertising}

$\mathrm{TU}$ is the satellite $\mathrm{DMB}$, which is a new medium that is both mobile and personal, and can be expected to experience increased demand in Korea. TNS research reported that the attention rate of DMB is relatively high (Figure 2).

Compared to broadcast visual media such as television, cable television (CATV) and satellite television, DMB is more likely to capture attention or capture at least as much as television. Moreover, the attention rate of DMB is similar to

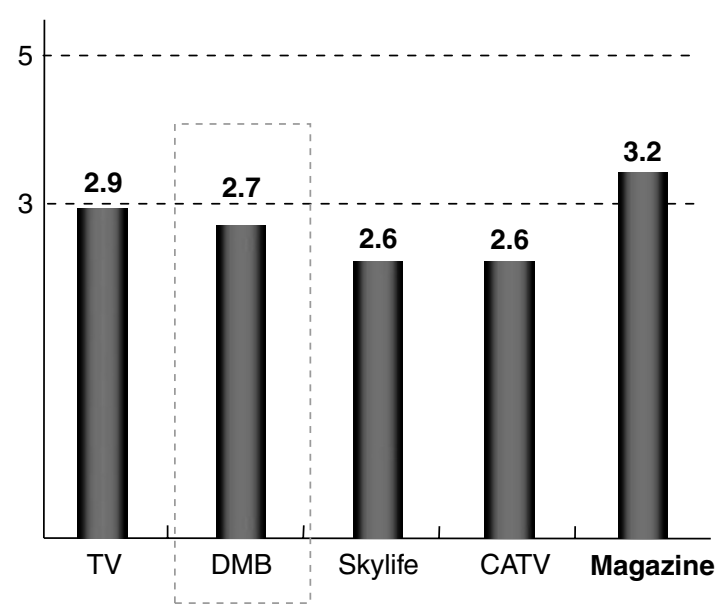

Figure 2: : The degrees of attention on advertising in different media

Source: TNS Research (2005)

that of a magazine that has been known to be a high attention getting medium. There are several reasons for this increased attention rate. First, the independent watching environment increases attention. Secondly, a mobile phone is a personal medium, allowing for highly accurate targeting. Mobile advertisements can get exposure when consumers are moving and are not affected by location. The main viewing time and location of $\mathrm{DMB}$ is mobile, which fixed television is not. According to research about DMB usage time and location, subscribers are more likely to watch DMB on break time at school or work, on the way to school or work and when they are moving or walking.

According to TNS research in 2005, the media image of satellite DMB is new, young, futureoriented, fashionable and original when compared to other media. The industry report of TU suggested that the majority of subscribers of satellite DMB are 20 to 30-year-old younger generation who are living in the metropolitan areas in South Korea, with more male subscribers than female. Moreover, they have high purchasing powers. Their education and income level are relatively high, and they are professional or whitecollar workers. The entertainment channels such as drama, game and others get high rating points. Large sports, games, popular dramas and show programmes also draw high rating points, 
according to the industry report of TU for 2006. Teenagers are the most avid viewers of $\mathrm{DMB}$, but 20 to 30 -year-old subscribers, who are the main target of TU, also constitute a considerable audience. According to the industry report of TU, time for viewing TU is the commute time of subscribers. Moreover, the general rating points of satellite DMB is similar to CATV, but the rating points of 20 to 30 -year-old males who watch DMB is higher than CATV's.

The successful mobile advertising cases of TU portray what messages they used to reach to their main target market. The client is SK Telecom's campaign that was carried out in January 2006. They advertised trying to improve the corporate image of SK Telecom by showing their support for popular Korean soccer players. The exposure rate was more than 1,000 times a month. Two interchangeable $15 \mathrm{~s}$ advertisements were presented at the same time. They were broadcasted at game time for the World Cup and WBC. Subscribers were also exposed to these advertisements during their individual commute time.

The second case under examination is that of the OB Beer Company. They wanted to advertise their product, Cass. The period of the advertising was from February to May in 2006 (three months). The exposure rate was 500 times a month. Owing to the time limits applicable to beer advertising, they set the advertising time to 10 p.m. Specifically, they used the channels that 20 to 30 -year-old male subscribers were watching most to carry their advertising messages.

\section{DISCCUSSION AND CONCLUSION}

The current case study explored the Korean mobile market and its executions of mobile advertising including DMB. The findings of case analysis show that Korean mobile market is quite attractive to international marketers, and its execution types of mobile advertising include mixed formats of mobile advertising. Particularly, personalisation is animated through consumer targeting and location. DMB advertising also uses personalisation advertising tactics to enhance the advertising effects and to reduce ad clutters or consumer ad avoidance. These findings are consistent with previous literature stressing the importance of personalisation in mobile advertising.

The findings of this study provide several managerial implications. First, South Korea is an attractive market in terms of mobile marketing and advertising. Given that South Korea started DMB services within the country, the South Korean market could easily become a test market for international marketers testing their new mobile services or mobile technologies. It should be, however, noted that the consumer cultures are different between Asians and Americans. In the survey of attitude towards mobile advertising service by $\mathrm{MMA}^{31}$, more than 60 per cent of respondents in Asian countries such as the Philippines, Malaysia and Indonesia indicate positive attitudes regarding the use of mobile advertising service. On the other hand, less than 20 per cent of respondents in the US or Germany want to receive mobile advertising. The success of the mobile business in South Korea is partly due to its collectivistic cultural orientation. In this regard, practical adaptations or alterations might be required when Western companies launch their mobile-related services to Korean or Asian markets.

Secondly, it should be noted that the case analysis shows the use of mixed forms of mobile advertising in South Korea. To make mobile advertising successful, it is required to incorporate various advertising tools into one advertising campaign. This is similar to the approach of integrated marketing communication (IMC). Given that mobile media hold mixed media characteristics such as text, video, audio and even interactivity, total advertising approaches would provide more effective outcomes. In addition, when implementing mobile advertising, it is suggested to seriously consider the personalisation approach. As previous literature and the current case study shows, personalisation is a critical factor in making mobile advertising successful. This is precisely because the cell phone is a private media and its characteristics are different from other traditional media. Furthermore, technological development could enable personalisation more easily and more accurately. 
There may be, however, an issue of privacy in executing mobile advertising. This would be the obstacle marketers and advertisers should overcome.

Based on the current case study, more refined future research of mobile advertising could be generated. Even though mobile is becoming a dominant media format, its advertising and marketing applications are in its early stages. Meanwhile, the effectiveness of mobile advertising may differ from culture to culture. Not only because of the culture differences, but varying economic or market situations may cause different attitudes or responses to mobile advertising among mobile phone users. Moreover, the different transaction and infrastructure systems of mobile phones may help to explain how mobile advertising is utilised differently among countries. We hope, however, that the current study can trigger more productive future research of mobile media, as well as mobile advertising or marketing.

\section{References}

1 Robins, F. (2003) 'The marketing of 3G', Marketing Intelligence $\mathcal{E}$ Planning, Vol. 21, No. 6, pp. 370-378.

2 Mobile Marketing Association (2007) Available at: http://www. mmaglobal.com (accessed 10th September, 2007).

3 Mobile Marketing Association (2007) Available at: http:// mmaglobal.com/modules/article/view.article.php/1153 (accessed 10th September, 2007).

4 Zoller, E., Housen, V. L. and Matthews, J. (2001) 'Wireless internet business models: Global perspective, regional focus', OVUM 2001 Report, pp. 1-64.

$5 \mathrm{Xu}, \mathrm{J}$. D. (2007) 'The influence of personalization in affecting consumer attitudes toward mobile advertising in China', Journal of Computer Information Systems, Vol. 47, No. 2, pp. 9-19.

6 Haghirian, P., Madlberger, M. and Tanuskova, A. (2005) 'Increasing advertising value of mobile marketing - An empirical study of Antecedents', Proceedings of the 38th Hawaii International Conference on System Sciences, 2005.

7 Li, H. and Lee, K. (2006) 'Mobile phones and mobile advertising: An Asian perspective', International Journal of Internet Marketing and Advertising, Vol. 3, No. 2, pp. 177-192.

8 Barwise, P. and Strong, C. (2002) 'Permission-based mobile advertising', Journal of Interactive Marketing, Vol. 16, No. 1, pp. 14-24.

9 DeZoysa, S. (2002) 'Mobile advertising needs to get personal', Telecommunications (International Edition), Vol. 36, No. 2, p. 8.

10 Tsang, M. M., Ho, S. and Liang, T. (2004) 'Consumer attitudes toward mobile advertising: An empirical study', International Journal of Electronic Commerce, Vol. 8, No. 3, pp. 65-78.

11 Buckley, R. (2007) 'Mobile to beat all advertising odds', available at: http://mmaglobal.com/modules/article/view.article.php/840 (accessed 10th October, 2007).
12 Li, H. and Stoller, B. (2007) 'Parameters of mobile advertising: A field experiment', International Journal of Mobile Marketing, Vol. 2, No. 1, pp. 4-11.

13 'It's a mobile world for broadband, too' Online Reporter: 18th June, 2005.

14 Steinbock, D. (2005) 'The Mobile Revolution: The Making of Mobile Services Worldwide', Thomson-Shore, Inc., London, UK.

15 'Mobile ad industry survey', Marketing Week', Vol. 24, No. 33, 27th September, 2001, p. 56.

16 Pagani, M. (2004) 'Full Internet Mobility in a 3G-4G Environment: Managing New Business Paradigms', EGEA, A.gra, Milano.

17 Jun, J. and Lee, S. (2007) 'Mobile media use and its impact on consumer attitudes toward mobile advertising', International Journal of Mobile Marketing', Vol. 2, No. 1, pp. 50-58.

18 Berendt, B., Gunther, O. and Spiekermann, S. (2005) 'Privacy in E-Commerce: Stated preferences vs. actual behaviour', Communications of the ACM, Vol. 48, No. 4, pp. 101-106.

19 Greer, T. H. and Murtaza, M. B. (2003) 'Web personalization: The impact of perceived innovation characteristics on the intention to use personalization', Journal of Computer Information Systems, Vol. 43, No. 3, pp. 50-55.

20 Miceli, G. N., Ricotta, F. and Costabile, M. (2007) 'Customizing customization: A conceptual framework for interactive personalization', Journal of Interactive Marketing, Vol. 21, No. 2, pp. 6-25.

21 Imhoff, C., Loftis, L. and Geiger, J. (2001) 'Building the Customer-Centric Enterprise', Data Warehousing Techniques for Supporting Customer Relationship Managemen, Wiley, New York.

22 Wind, J. and Rangaswamy, A. (2001) 'Customerization: The next revolution in mass customization', Journal of Interactive Marketing, Vol. 15, No. 1, pp. 13-32.

23 Coner, A. (2003) 'Personalization and customization in financial portals', Journal of American Academy of Business, Vol. 2, No. 2, pp. $498-504$.

24 Roberts, M. L. (2003) 'Internet Marketing: Integrating Online and Offline Strategies', McGraw-Hill/Irwin, Boston.

25 Vesanen, J. and Raulas, M. (2006) 'Building bridges for personalization: A process model for marketing', Journal of Interactive Marketing', Vol. 20, No. 1, pp. 5-20.

26 Ody, P. (2001) 'The Mobile Consumer', http://www.ft.com Special reports/Understanding 3G (accessed 6th June).

27 Kim, S. D. (2002) 'Korea: personal meanings', in Katz, J. E. and Aakhus, M. (ed.), 'Perpetual Contact: Mobile Communication, Private Talk, Public Performance', Cambridge University Press, Cambridge, UK, New York, pp. 63-79.

$28 \mathrm{Kim}, \mathrm{H}$. and Kwon, N. (2003) 'The advantage of network size in acquiring new ubscribers: A conditional logit analysis of the Korean mobile telephony market', Information Economics and Policy, Vol. 15, pp. 17-33.

29 Informa UK Ltd (2003) 'How the South Korean operators succeeded in selling $2.5 \mathrm{G}$ and $3 \mathrm{G}$ Services to their customers', 3G Mobile, Vol. 5, No. 15, p. 10.

30 Moon, I. (2007) 'South Koreans want their M-TV!', Business week Online, 6th August, 2007, Monday, available at: http://www. businessweek.com/globalbiz/content/aug2007/gb2007083_ 146756.htm.

31 KTF mhows Mail Magazine, Vol. 21, May, 2007, http://www. mhows.com. 